\title{
Jogos Cooperativos e Argumentação: Caminhos para uma Formação Crítica e Reflexiva de Licenciandos em Matemática ${ }^{1}$
}

\section{Cooperative Games and Argumentation: Pathways for a Critical and Reflective Formation of Teaching Students in Mathematics}

\author{
Carlos Antonio da Silva Lopes*a; Sylvia De Chiaro ${ }^{\mathrm{a}}$
}

aUniversidade Federal de Pernambuco. PE, Brasil.

*E-mail: carlos.lopess@live.com

\begin{abstract}
Resumo
O presente artigo se propõe a analisar o impacto de um curso de extensão sobre as relações entre jogos cooperativos e argumentação para uma prática crítica e reflexiva de licenciandos de Matemática de uma Universidade Federal de ensino superior. Para cada momento do curso foram desenvolvidas atividades que permitiram que os 05 licenciandos participantes tivessem contato tanto com os pressupostos teóricos sobre os jogos cooperativos e argumentação, como também vivenciassem atividades práticas que os mobilizaram na utilização dos conhecimentos adquiridos para a construção de um jogo cooperativo-argumentativo como produto final. Ao analisar os dados pudemos concluir que os licenciandos conseguiram desenvolver suas potencialidades cooperativas e argumentativas e foram capazes de elaborar um jogo que denotou a capacidade dos mesmos de pensar em como fazer emergir e manter a argumentação em um contexto cooperativo. Assim, além do curso de extensão ter contribuído para a formação crítica e reflexiva dos licenciandos envolvidos, a experiência formativa pela qual passaram ajudou-os na promoção de situações potencializadoras de um aprendizado igualmente crítico e reflexivo em suas salas de aula.
\end{abstract}

Palavras-chave: Argumentação. Jogos Cooperativos. Pensamento Crítico-Reflexivo. Formação Docente. Educação Matemática.

\begin{abstract}
This article aims to analyze the impact of an extension course about the relationship between cooperative games and argumentation, in order to offer critical and reflective practice to teaching students in Mathematics from a Federal University. For each phase of the course, activities were developed that allowed the 05 participating undergraduates to both have contact with the theoretical assumptions about cooperative games and argumentation, as well as experience practical activities that mobilized them in the use of the acquired knowledge to build a cooperativeargumentative game as a final product. By analyzing the data, we concluded that the undergraduates were able to develop their cooperative and argumentative potential and were capable of developing a game that showed their ability to think about how to make the argumentation emerge and be maintained in a cooperative context. Thus, in addition to the extension course having contributed to the critical and reflective training of the undergraduates involved, the formative experience they went through helped them to promote situations that equally enhanced critical and reflective learning in their classrooms.
\end{abstract}

Keywords: Argumentation. Cooperative Games. Reflexive-Critical Thinking. Teacher Training. Mathematics Education.

\section{Introdução}

Em nosso trabalho o interesse por estudar os jogos cooperativos e a argumentação na formação de professores é resultado das experiências, reflexões e questionamentos construídos pelo primeiro autor em sua graduação em Matemática, bem como na sua atuação profissional. De forma inicial, por meio de projetos de extensão e discussões entre colegas e professores, pudemos compreender melhor as potencialidades da argumentação em situações de ensino e aprendizagem. Vimos que a mesma possibilita a construção de conhecimentos e o desenvolvimento do pensamento crítico e reflexivo (Leitão, De Chiaro \& Cano, 2016; Leitão, 1999, 2013;).

Ao adentrarmos nas discussões acerca dos jogos cooperativos, compreendemos que estes propõem a busca pela solução de um desafio através de atitudes de contribuição, e nestes, os jogadores precisam ter em mente que ganhar/perder não necessariamente é o que importa, mas sim que todos cooperem, negociem e alcancem o objetivo do jogo (Orlick, 1978). Dessa maneira, apontamos a coerência existente entre um jogo nesta perspectiva e o uso da argumentação durante a dinâmica do mesmo, uma vez que na nossa proposta, a argumentação assume papel central na negociação de concepções alternativas de forma colaborativa e não como forma de embate, no qual o argumento de um indivíduo deva se sobrepor e "ganhar" do outro. Assim, a proposta desse estudo volta-se para a convergência entre esse tipo de jogo, cooperativo, e a argumentação, pois, em essência acreditamos nas profícuas vantagens educativas dessas duas estratégias. Reflexões teóricas sobre a relação entre os jogos cooperativos e a argumentação que apoiam esse estudo podem ser encontradas em Lopes, Rodrigues \& Rodrigues (2020).

1 Este artigo decorre dos resultados da pesquisa da dissertação do primeiro autor. Pesquisa realizada no âmbito do Mestrado em Educação em Ensino de Ciências e Matemática. 
Assumimos a argumentação como uma organização discursiva capaz de promover o desenvolvimento metacognitivo, uma vez que leva os indivíduos envolvidos a tomarem seus pensamentos como objetos de reflexão (De Chiaro \& Aquino, 2017; De Chiaro \& Leitão, 2005). Os indivíduos argumentam cotidianamente mesmo sem os conhecimentos específicos sobre argumentação ou sobre o campo de conhecimento que certo debate esteja inserido. Porém, mesmo que possamos considerar a possibilidade espontânea de surgir a argumentação em sala de aula, inclusive entre crianças (Leitão, 2011), os professores não devem esperar este "acaso", mas sim aprender a fazê-la emergir e mantê-la intencionalmente. Nesse sentido, atentamos para a formação de um(a) professor(a) que tenha não só consciência da importância dessa intencionalidade, mas que permita que seu alunado tenha acesso a esse tipo de discurso a partir da inclusão, em seu planejamento didático, de uma argumentação deliberada e com qualidade acadêmica.

Nesta direção, tivemos como um dos principais objetivos da presente pesquisa, analisar o impacto de um curso de extensão, aplicado à graduandos em licenciatura em Matemática, sobre as relações entre jogos cooperativos e argumentação e suas potencialidades no desenvolvimento de uma prática docente crítica e reflexiva. Justificamos com isso a importância do uso da argumentação para essa prática e, também para que esses futuros docentes possam ter contato com este tipo de discurso em situações que os permitam tornarem-se, gradativamente, indivíduos hábeis no ato de argumentar, de mediar situações de argumentação e também de serem críticos e reflexivos.

Essa formação foi efetivada através do desenvolvimento de um curso de extensão no qual licenciandos em Matemática puderam construir conhecimentos acerca da argumentação, dos jogos cooperativos e da relação existente entre estes dois. Além disso, os participantes tiveram, como atividade final do curso, a construção de um jogo que unisse estas duas estratégias, um jogo que fosse, portanto, cooperativoargumentativo.

Aconstrução deste jogo foi baseada em critérios construídos pelos participantes em um dos momentos do curso de extensão, com base em suas reflexões e experiências vivenciadas no decorrer do mesmo. Esta produção envolveu um ensino/ aprendizado dos participantes em relação à argumentação e aos jogos na perspectiva cooperativa. Com esse momento formativo, o objetivo esteve também voltado para formá-los em argumentação, possibilitando-os argumentar entre eles e fazendo-os entender o potencial da argumentação nas aulas de Matemática. Além disso, esperávamos que os licenciandos desenvolvessem o entendimento de que essa articulação (argumentação - jogos cooperativos) é deveras produtiva na construção do conhecimento de forma crítica e reflexiva. Assim, tivemos como norteador o seguinte questionamento: Qual o impacto de um curso de extensão sobre as relações entre jogos cooperativos e argumentação para uma prática crítica e reflexiva de futuros professores de Matemática?

\section{Pensamento e Linguagem: Aprendizagem e Desenvolvimento Cognitivo}

Ao pensar na convivência entre seres humanos, refletimos como estes interagem, bem como se utilizam da linguagem. Para além do papel de comunicação, entendemos que há uma correlação entre a linguagem, aprendizado e o desenvolvimento destes seres humanos. Com o objetivo de fundamentarmos as bases epistemológicas da concepção de linguagem apontada em nosso trabalho, abordaremos os basilares conceitos da Teoria Sócio-interacionista de Lev Semyonovich Vygotsky.

Vygotsky $(1993,2010)$ defende uma relação constitutiva entre linguagem e pensamento e entre aprendizado e desenvolvimento, evidenciando a importância das relações sociais nesse sentido. Dentre tantas importantes ideias que marcam a teoria desse autor, o conceito de Zona de Desenvolvimento Proximal (ZDP) nos ajuda mais pontualmente a justificar a relação dessa teoria com o presente estudo. Vygotsky definiu a ZDP como a distância entre o nível de desenvolvimento potencial (NDP) de um indivíduo, sendo esse caracterizado pela solução de problemas sob colaboração de adultos ou colegas mais capazes, e o nível de desenvolvimento real (NDR), determinado pela resolução de problemas de forma independente. Quando nos referimos ao papel do professor no processo de construção do aprendizado dos estudantes, o compreendemos como mediador das ações que conduzirão estes estudantes nesse movimento do NDP ao NDR, sendo o maior momento pedagógico do professor sua atuação na ZDPde seus alunos. Essa atuação se dá a partir de suas mediações discursivas intencionais e ainda no planejamento de atividades que facilitem essa movimentação. Neste sentido, jogos e brincadeiras desempenham papéis primordiais, pois, além de promoverem a interação social, possibilitam a criação de ZDPs, uma vez que desafiam o participante, instigando-o a ser capaz de controlar seu comportamento, experimentar habilidades ainda não consolidadas no seu repertório, criar modos de operar mentalmente e de agir no mundo que desafiam o conhecimento já internalizado, impulsionando o desenvolvimento de funções embrionárias de pensamento (Pimentel, 2008).

É partir dessas reflexões que Vygotsky (1993) defende a potencialidade do desenvolvimento da ZDP através do jogo. Ao se criar a ZDP dentro do jogo, se permite que a ação do outro, quando bem conduzida, possa diminuir a distância entre o NDP e o NDR do indivíduo. Isto ocorre visto que o mesmo restaura no campo intrapessoal o que a princípio só existia no campo visual do jogo, contribuindo para a aprendizagem e o desenvolvimento de funções psicológicas que estão no caminho de se consolidar.

Nesse ponto fica mais clara a proposta desse estudo: a formação de professores que sejam capazes de formular e utilizar jogos cooperativos-argumentativos como recursos 
mediadores nesse processo de desenvolvimento. Isso porque, se segundo Vygotsky (1993), o aprendizado precede o desenvolvimento, o ensino (e nele se inclui o planejamento de estratégias pedagógicas) deve se antecipar ao que o aluno ainda não sabe e nem é capaz de realizar sozinho. Todo aprendizado é mediado e isso torna o papel do ensino e do professor ativo e determinante. Mais especificamente, em nossa proposta do curso de extensão damos ênfase a pensar no professor em formação enquanto mediador das ações a serem desenvolvidas no jogo construído de forma a tentar orientar os alunos, por meio de ações reflexivas provenientes do ato de argumentar, para a aprendizagem dos conceitos matemáticos que os levarão a níveis mais sofisticados de desenvolvimento.

\section{Jogos Cooperativos e Argumentação}

De acordo com Grando (1995), não é tarefa fácil definir jogo, uma vez que tentar defini-lo pode acarretar a limitação de seu próprio conceito. Segundo Kishimoto (1994) a variedade de fenômenos considerados como jogo mostra a complexidade da tarefa de defini-lo. Para Huizinga (2000), um dos precursores dos estudos que tentaram elencar características sobre jogos, o jogo é visto como uma atividade ligada à cultura e pode assumir sentido em toda e qualquer atividade humana. Para este autor, o jogo é uma atividade voluntária, ação na qual o indivíduo, ao participar de sua dinâmica, deve estar motivado e interessado a ponto de se submeter ao tempo destinado à sua aplicação e às suas regras. Isto é, para jogar, o indivíduo precisa se sentir livre e não pode estar sujeito diretamente às ordens, pois, nesse caso, o jogo passa a ser considerado uma tarefa.

Dentre as inúmeras concepções acerca dos jogos, neste estudo, o mesmo é pensado em caráter pedagógico cujo objetivo é ser meio para o desenvolvimento de aprendizagens e raciocínios para aqueles que interagem durante a dinâmica do mesmo. Como bem coloca Grando (1995, p.44), o jogo dito pedagógico apresenta-se produtivo ao professor que busca nele um aspecto instrumentador e, portanto,

facilitador à aprendizagem do aluno e, também, produtivo ao aluno, que desenvolve sua capacidade de pensar, refletir, analisar, levantar hipóteses, testá-las e avalia-las, além do desenvolvimento da autonomia e da socialização propiciadas pelo movimento do jogo.

Dessa forma, também nos alinhamos com Mattos (2009) quando a autora evidencia que o jogo assume um caráter de instrumento pedagógico capaz de ser motivador no ensinoaprendizagem de Matemática, uma vez que este preconiza o desenvolvimento da autonomia, do senso de liderança, da criação e aplicação de estratégias de solução de problemas, da atenção, do estímulo à imaginação, além de contribuir para a socialização. Assim, os jogos em situações didáticas surgem como uma proposta de aliar a construção do conhecimento ao prazer. Nesta direção, Itacarambi (2013) expressa que o jogo do ponto de vista pedagógico é desafiador, permite a apresentação dos conteúdos de modo atrativo, favorece a criatividade na elaboração de estratégias e persistência na busca de solução. Ele simula situações problemas que exigem soluções imediatas, o que estimula o planejamento das ações.

Ao tratarmos acerca dos jogos cooperativos, partimos do pressuposto de que comportamentos competitivos e cooperativos não são simplesmente inerentes aos seres humanos, mas também aprendidos socialmente. Para Orlick (1978), na competição o objetivo está relacionado à rivalidade, na qual os interesses individuais são latentes e o oponente deve ser impedido de atingir seus objetivos. Os jogos cooperativos surgiram para tentar romper com o exagero das relações de competição, que fomentavam cada vez mais o individualismo (Brotto, 2013). Segundo Brotto (2013), nós professores precisamos refletir acerca de que tipo de jogo utilizar e que tipo de educação e sociedade temos a intenção de desenvolver através destes jogos com nossos alunos.

Orlick (1978, p.123) ainda aponta que "o objetivo primordial dos jogos cooperativos é criar oportunidades para o aprendizado cooperativo e a interação cooperativa prazerosa". Assim, uma situação de cooperação é aquela em que para que o objetivo de um indivíduo possa ser alcançado, todos os demais deverão igualmente atingir seus respectivos objetivos (Brotto, 2013). A cooperação deve propiciar condições para a interdependência entre seus participantes, enfatizando a importância da ajuda do outro.

Antes de compreendermos melhor as relações que nos fizeram concluir a potencialidade da união entre essas duas estratégias, argumentação e jogos cooperativos, faremos um delineamento acerca da concepção de argumentação que nos ancora, bem como dos elementos que a constituem.

A argumentação é aqui entendida como uma atividade de natureza discursiva privilegiada se comparada a outros tipos de discurso, uma vez que compele o indivíduo a refletir sobre concepções alternativas e negociar significados. Ela proporciona o exercício de uma forma sofisticada de pensamento: o crítico e reflexivo. De pensadores críticoreflexivos esperamos que testem e avaliem seus argumentos à luz de perspectivas alternativas não só em situações discursivas em que seus argumentos são desafiados pela contra argumentação de outrem, mas que também o façam através da ponderação sistemática dos prós e contras relativos às posições que defendem (Leitão, 2011).

Para Leitão (2011), argumentação, reflexão e construção do conhecimento são processos inter-relacionados. $\mathrm{O}$ ato de argumentar está presente em diferentes momentos da vida cotidiana. Argumentamos quando defendemos nossos posicionamentos e direitos, quando tomamos decisões, entre outras situações que envolvem diferentes perspectivas. Esta só acontece quando existe controvérsia, divergência de pontos de vistas em que os indivíduos levantarão argumentos com o intuito principal de convencer o outro de seu posicionamento e/ou refutar os argumentos interpostos pelo outro.

A presença de concepções alternativas dentro da atividade argumentativa caracteriza as figuras do proponente 
e do oponente. Ao proponente cabe oferecer razões que sustentem seu posicionamento (argumento - A), examinar os contra-argumentos (CA) levantados pelo oponente e a eles conceder uma resposta $(\mathrm{R})$, sendo esses três os elementos que compõem o que Leitão (2007) chama de unidade triádica da argumentação. Ao oponente cabe levantar questionamentos (construir os CAs) que venham diminuir ou colocar em dúvida os posicionamentos iniciais levantados pelo proponente.

Por meio das reflexões da autora citada, podemos apontar a importância dos processos que caracterizam a argumentação: justificação de pontos de vista, exame e resposta a contraargumentos. Esses movimentos estimulam o indivíduo a passar de um nível de funcionamento cognitivo, que produz ideias sobre fenômenos, a outro nível no qual seu pensamento passa a ser objeto de sua própria reflexão, passando a um funcionamento metacognitivo. Assim, a argumentação, quando assume um papel cooperativo, propicia que proponente e oponente busquem chegar a um consenso de forma crítica e reflexiva.

A partir disso, podemos delimitar um ambiente argumentativo como aquele no qual alguns elementos se fazem presentes: pontos de vista que divergem entre si; justificativas destes, contra argumentos que são os responsáveis pelo confronto e as possíveis respostas aos contra-argumentos. Assim, segundo Leitão (2011, p.20) “é exatamente na formulação de resposta aos contra-argumentos, pelo proponente, que novas possibilidades de entendimento do tópico discutido podem então ser geradas".

Leitão (2011), ao nos relatar os possíveis desafios encontrados ao se utilizar a argumentação na sala de aula, nos aponta que, como o objetivo neste ambiente é promover a construção crítica de "conhecimentos canônicos", não se consegue, por vezes, enxergar que estes sejam passíveis de debatibilidade - principalmente aqueles relacionados à área matemática. No entanto, a autora elucida que os conteúdos não precisam ser, em sua essência, controversos, mas podem ser criadas condições para que estes sejam postos em debate e passem a ser refletidos criticamente. As próprias ações discursivas do professor podem ser utilizadas intencionalmente para construir esse espaço de debatibilidade de um tema. De Chiaro e Leitão (2005) apontam que existem três tipos de ações discursivas que podem ser utilizadas pelo professor com o intuito de se trabalhar com a argumentação, fazendo-a emergir e mantendo-a. São elas: (1) ações em nível pragmático - autorizando e estimulando a ocorrência da argumentação; (2) argumentativo - participando da discussão junto aos alunos e (3) epistêmico - trazendo informações e formas de raciocínio próprios do domínio do conhecimento em questão. Mas a debatibilidade também pode ser promovida a partir da construção de estratégias didáticas com esse fim.

É nesse viés que acreditamos que o objetivo em um jogo cooperativo possa vir a ser alcançado por meio do uso da argumentação. O objetivo de um jogo como este coincidiria com o da argumentação em sala de aula: a construção do conhecimento de determinado conteúdo de forma reflexiva, desafiadora e compartilhada. As situações problema criadas no jogo cooperativo-argumentativo podem ser apresentadas por intermédio de uma controvérsia e os alunos, na busca para solucioná-la de maneira consensual, se utilizam da argumentação e, de forma conjunta e cooperativa, se unem para atingir o objetivo do jogo.

A união dessas propostas (jogos cooperativos e argumentação) é o que denominados 'jogo potencialmente cooperativo e argumentativo', já que as situações a serem desenvolvidas dentro deste devem ser pensadas de forma a fazer com que seus jogadores argumentem cooperativamente. Isso deve se dar pela tentativa de criar situações dentro do jogo que permitam que os estudantes atuem reflexiva e criticamente sobre elas, planejando suas ações conjuntamente na busca por um objetivo comum.

\section{Percursos Metodológicos}

A pesquisa foi realizada em uma instituição pública federal de ensino superior. Foi proposto um curso de extensão para estudantes de Licenciatura em Matemática, que objetivou uma formação em jogos cooperativos e argumentação de forma a os tornarem aptos à construção de um jogo que unisse essas duas estratégias. O curso de extensão foi intitulado de "Jogos Cooperativos e Argumentação: Caminhos para uma prática crítica e reflexiva". Contou com a participação efetiva e integral de 3 dos 5 licenciandos em Matemática inicialmente inscritos - todos cursando o $7^{\circ}$ período da graduação. Esses dois a menos, por motivos pessoais, participaram de parte do curso, mas desistiram antes do término das atividades.

Dividimos o curso em 4 momentos, nos quais, para além das observações e anotações feitas, foram também realizadas videogravações com o intuito de captarmos o máximo de informações possíveis dos participantes da pesquisa (falas, entonações, expressões físicas, faciais, etc.). O Momento 1 foi dedicado à temática 'Jogos' e o momento 2 à temática 'Argumentação'. Nesses dois momentos, foram trabalhados aspectos teóricos dos dois temas, assim como exercitadas atividades práticas de ambos. O módulo 3 articulou as duas temáticas e se intitulou 'Jogos Cooperativos e Argumentação'. Nele, além de discussões teóricas sobre a articulação das duas temáticas, os licenciandos tiveram como atividade a elaboração de critérios necessários para a construção de um jogo potencialmente cooperativo e argumentativo. No último módulo, o 4, os licenciandos foram demandados a construir um jogo cooperativo e argumentativo com base nos conhecimentos adquiridos nos momentos anteriores e nos critérios elaborados por estes. Os dados gerados pelas atividades de cada módulo (que poderão ser vistas em mais detalhes nos Quadros 1, 2, 3 e 4) forneceram os elementos necessários para análise e resposta aos objetivos específicos da pesquisa. No total foram 11 encontros, com carga horária total de 44h, realizados entre julho e novembro de 2018.

Para compreendermos melhor a pesquisa, elencamos nos 
quadros abaixo os objetivos específicos percorridos com o intuito de atingirmos o objetivo geral do estudo relacionados aos momentos do curso de extensão. Para cada um dos objetivos, mostramos as atividades práticas realizadas no curso que serviram para a construção dos dados e os critérios de análise utilizados para responder aos mesmos.

Quadro 1 - Construção dos dados e critérios de análise para o objetivo específico 1, ocorrida no momento 1 do curso: Jogos

\begin{tabular}{|c|c|c|}
\hline $\begin{array}{c}\text { Objetivo } \\
\text { Específico } 1\end{array}$ & Atividades & $\begin{array}{c}\text { Critérios/ } \\
\text { Unidades de } \\
\text { Análise }\end{array}$ \\
\hline $\begin{array}{c}\text { Analisar } \\
\text { aspectos da } \\
\text { apropriação das } \\
\text { potencialidades } \\
\text { cooperativas } \\
\text { dos } \\
\text { licenciandos ao } \\
\text { longo do curso } \\
\text { de extensão }\end{array}$ & $\begin{array}{l}\text { 1. Criação de um jogo } \\
\text { competitivo } \\
\text { 2. Transformação de } \\
\text { um jogo competitivo } \\
\text { (CONTIG 60) para } \\
\text { uma perspectiva } \\
\text { cooperativa. } \\
\text { 3. Transformação do } \\
\text { jogo competitivo } \\
\text { da atividade 1, para } \\
\text { uma perspectiva } \\
\text { cooperativa. }\end{array}$ & $\begin{array}{l}\begin{array}{l}\text { 1. Ausência de } \\
\text { situações de } \\
\text { competição; }\end{array} \\
\text { 2. Demandas de } \\
\text { interdependência } \\
\text { entre } \\
\text { participantes; }\end{array}$ \\
\hline
\end{tabular}

Fonte: Dados da pesquisa.

Esperávamos nesse objetivo que os licenciandos conseguissem identificar os componentes essenciais de uma prática cooperativa (Brotto, 2013; Orlick, 1978), bem como desenvolver suas potencialidades cooperativas.

Quadro 2 - Construção dos dados e critérios de análise para o objetivo específico 02, ocorrida no momento 2 do curso: Argumentação

\begin{tabular}{|c|c|c|}
\hline $\begin{array}{c}\text { Objetivo } \\
\text { Específico } 2\end{array}$ & Atividades & $\begin{array}{c}\text { Critérios/ } \\
\text { Unidades de } \\
\text { Análise }\end{array}$ \\
\hline \multirow{4}{*}{$\begin{array}{c}\text { Analisar } \\
\text { aspectos da } \\
\text { apropriação das } \\
\text { potencialidades } \\
\text { argumentativas } \\
\text { dos licenciandos } \\
\text { ao longo do } \\
\text { curso de extensão }\end{array}$} & $\begin{array}{l}\text { 1. Debate sobre o uso de } \\
\text { "Agrotóxicos" }\end{array}$ & $\begin{array}{l}\text { Unidade triádica } \\
\text { de Leitão }\end{array}$ \\
\hline & $\begin{array}{l}\text { 2. Identificação } \\
\text { dos elementos da } \\
\text { argumentação em textos } \\
\text { sobre 'Maconha' e } \\
\text { 'Reforma trabalhista' e } \\
\text { em expressões aleatórias } \\
\text { trazidas pelo professor }\end{array}$ & $\begin{array}{l}\text { Unidade triádica } \\
\text { de Leitão }\end{array}$ \\
\hline & $\begin{array}{l}\text { 4. Identificação de ações } \\
\text { discursivas }\end{array}$ & $\begin{array}{c}\text { Ações } \\
\text { discursivas de } \\
\text { De Chiaro e } \\
\text { Leitão }\end{array}$ \\
\hline & $\begin{array}{l}\text { 5. Autoanálise } \\
\text { videográfica do } \\
\text { debate sobre } \\
\text { "Agrotóxicos" }\end{array}$ & $\begin{array}{l}\text { Unidade triádica } \\
\text { de Leitão }\end{array}$ \\
\hline
\end{tabular}

Fonte: Dados da pesquisa.

Com relação ao segundo objetivo específico, nos referimos às potencialidades argumentativas a serem apropriadas pelos licenciandos. Entendemos essas potencialidades como aquelas que permitiriam os licenciandos compreenderem, identificarem e utilizarem os elementos da argumentação, como também identificarem em textos escritos ou debates as ações discursivas específicas que poderiam ser utilizadas por professores para a emergência da argumentação em um contexto de sala de aula.

Aqui as análises foram feitas a partir dos dados das atividades práticas do momento 2, detalhadas acima. Duas unidades de análise foram utilizadas: (1) na tentativa de identificarmos a presença de situações argumentativas foi utilizada a unidade triádica proposta por Leitão (2007) - A; CA e R e (2) para identificar a presença de ações discursivas específicas que o professor pode se utilizar em sala de aula de forma a garantir a emergência da argumentação, foram utilizadas as ações propostas por De Chiaro \& Leitão (2005) e Leitão (2011) - ações pragmáticas; argumentativas e epistêmicas.

Quadro 3 - Construção dos dados e critérios de análise para o objetivo específico 3, ocorrida no momento 3 do curso: Jogos Cooperativos e Argumentação

\begin{tabular}{|c|c|c|}
\hline $\begin{array}{c}\text { Objetivo } \\
\text { Específico } 3\end{array}$ & Atividades & $\begin{array}{c}\text { Critérios/ } \\
\text { Unidades de } \\
\text { Análise }\end{array}$ \\
\hline $\begin{array}{l}\text { Analisar elementos } \\
\text { relacionados a } \\
\text { apropriação das } \\
\text { potencialidades } \\
\text { cooperativas e } \\
\text { argumentativas } \\
\text { pelos licenciandos } \\
\text { na elaboração } \\
\text { dos critérios } \\
\text { necessários para a } \\
\text { construção de um } \\
\text { jogo cooperativo } \\
\text { argumentativo }\end{array}$ & $\begin{array}{c}\text { Elaboração e } \\
\text { explicação feitas } \\
\text { pelos licenciados } \\
\text { dos critérios } \\
\text { que julgavam } \\
\text { necessários para } \\
\text { a criação de um } \\
\text { jogo cooperativo } \\
\text { argumentativo. }\end{array}$ & $\begin{array}{c}\text { Critérios } \\
\text { construídos } \\
\text { previamente pelos } \\
\text { pesquisadores }{ }^{2} \\
\text { mediante os } \\
\text { estudos do que } \\
\text { apontam os autores } \\
\text { Orlick (1978) e } \\
\text { Leitão (2011). }\end{array}$ \\
\hline
\end{tabular}

Fonte: Dados da pesquisa.

No que tange ao objetivo específico 3, o foco era entender a possível apropriação das potencialidades cooperativas e argumentativas pelos licenciandos. Essa análise esteve pautada nos critérios e regras que os licenciandos elaboraram acerca do que acreditavam ser necessário para a construção de um jogo cooperativo argumentativo. Comparamos os critérios por eles elencados com os construídos por nós, pesquisadores, previamente, para em seguida, analisar até que ponto havia convergências, divergências ou expansões entre os mesmos. Quanto mais próximos de nossos critérios fossem os elaborados por eles, poderíamos concluir que maiores teriam sido a apropriação e o desenvolvimento das potencialidades cooperativas e argumentativas dos licenciandos. 
Quadro 4 - Construção dos dados e critérios de análise para o objetivo específico 04 , ocorrida no momento 4 do curso: Construção do jogo

\begin{tabular}{|c|c|c|}
\hline Objetivo & Atividades & $\begin{array}{c}\text { Critérios/ } \\
\text { Unidades de } \\
\text { Análise }\end{array}$ \\
\hline $\begin{array}{c}\text { Específico 04: } \\
\text { Analisar a } \\
\text { potencialidade } \\
\text { cooperativa e } \\
\text { argumentativa do } \\
\text { jogo elaborado } \\
\text { pelos licenciandos } \\
\text { ao final do curso de } \\
\text { extensão. }\end{array}$ & $\begin{array}{c}\text { jogo cooperative } \\
\text { argumentativo e } \\
\text { pelos licenciandos. }\end{array}$ & $\begin{array}{c}\text { e Critérios } \\
\text { construídos pelos } \\
\text { pesquisadores } \\
\text { e os critérios } \\
\text { elencados pelos } \\
\text { licenciandos para a } \\
\text { construção de um } \\
\text { jogo cooperativo } \\
\text { argumentativo. }\end{array}$ \\
\hline
\end{tabular}

Após a elaboração dos critérios, solicitamos aos licenciandos que construíssem um jogo cooperativo argumentativo tendo como base os conhecimentos construídos até então no curso. Essa construção serviu de subsídio para que pudéssemos analisar a potencialidade cooperativa $\mathrm{e}$ argumentativa do jogo criado pelos licenciandos. A análise foi feita através da comparação entre o jogo construído e os critérios elaborados por eles, de modo que pudéssemos perceber até que ponto ambos convergiam. Os critérios foram identificados como cumpridos ou não de acordo com as regras do jogo criado pelos licenciandos. Para tanto, elaboramos previamente descritores ${ }^{3}$ que nos ajudaram a identificar nessas regras os critérios essenciais para a construção de um jogo cooperativo argumentativo. Estes descritores nos ajudaram a compreender a possível potencialidade deste jogo cooperativo-argumentativo. Embora não houvesse uma garantia de que este viesse a propiciar toda sua potencialidade, analisamos no sentido da contribuição das regras para que isto pudesse ocorrer.

Foram transcritas as falas dos participantes durante as atividades. Cada fala foi identificada por turnos enumerados, sendo o primeiro identificado como (T01), o segundo (T02) e assim sucessivamente. Com o objetivo de preservar as identidades dos participantes, optamos por atribuir pseudônimos, neste caso, utilizamos nomes de constelações (Andrômeda, Áquila, Orion, Pégasus \& Hydra). Os trechos que referenciamos em nossas análises estarão em negrito.

\section{Resultados e Análises}

O presente estudo, como mencionado na introdução, teve por objetivo analisar o impacto de uma situação de formação para licenciandos em Matemática, sobre as relações entre jogos cooperativos e argumentação. Para cada um dos objetivos específicos, foi selecionado um pequeno recorte de alguma das análises realizadas para servir de exemplo do estudo.

No que tange ao primeiro objetivo específico, o de analisar aspectos da apropriação das potencialidades cooperativas dos licenciandos ao longo do curso de extensão, descreveremos e analisaremos recortes de passos que os graduandos seguiram para a adaptação de jogos da perspectiva competitiva para a cooperativa. Essas adaptações nos ajudaram a identificar aspectos relacionados à possível apropriação das potencialidades cooperativas pelos licenciandos.

Para melhor compreensão desse momento, torna-se importante detalhar suas etapas. Primeiro solicitamos aos licenciandos que criassem um jogo competitivo. Em seguida, apresentamos alguns jogos competitivos e pedimos que os adaptassem para a perspectiva cooperativa. Como atividade posterior, solicitamos que adaptassem o jogo competitivo criado pelos mesmos no início para uma versão cooperativa. Vale salientar que quando construíram o jogo competitivo, os licenciandos não sabiam que posteriormente teriam que fazer essa adaptação. O quadro abaixo traz um recorte acerca do referido jogo competitivo criado pelos licenciandos na primeira atividade proposta.

Quadro 5 - Jogo Competitivo criado pelos participantes do curso de extensão

\begin{tabular}{|c|c|}
\hline Detalhes sobre o jogo criado & Regras (R) \\
\hline 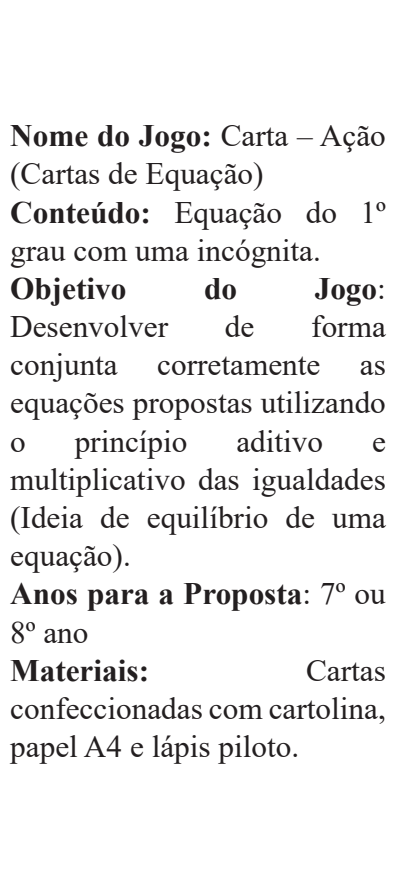 & $\begin{array}{l}\text { R1. A sala poderá ser dividida } \\
\text { em grupos/duplas/trios/ } \\
\text { individual } \\
\text { R2. Cada grupo/dupla deverá } \\
\text { desenvolver as equações } \\
\text { propostas usando as cartelas } \\
\text { com símbolos e números, } \\
\text { montando a resolução correta } \\
\text { da equação de forma gradativa } \\
\text { e detalhada se utilizando } \\
\text { do princípio aditivo e } \\
\text { multiplicativo das igualdades. } \\
\text { R3. Quem terminar de } \\
\text { resolver primeiro a equação } \\
\text { vence. } \\
\text { R4. Caso o grupo/dupla/ } \\
\text { trio/individual que disse que } \\
\text { terminou primeiro errar a } \\
\text { resolução, este será impedido } \\
\text { de refazer e um tempo será } \\
\text { dado aos demais participantes } \\
\text { para que continuem o } \\
\text { processo. }\end{array}$ \\
\hline
\end{tabular}

Fonte: Dados da pesquisa.

O Quadro 6 aponta as novas regras do jogo criado pelos licenciandos, agora em sua versão cooperativa. 
Quadro 6 - Jogo transformado pelos licenciados para a versão cooperativa

\begin{tabular}{|l|}
\hline \multicolumn{2}{|c|}{ Regras do jogo criado: Versão Cooperativa } \\
\hline A sala deverá ser dividida em grupos; \\
1. Uma metade dos participantes de cada grupo ficará \\
responsável por resolver a parte algébrica das equações e \\
a outra metade ficará responsável pela resolução da parte \\
numérica; \\
2. Cada grupo deverá desenvolver as equações propostas (que \\
estarão expostas em mesas) usando as cartelas com símbolos \\
e números, montando a resolução correta da equação de \\
forma gradativa e detalhada se utilizando do princípio \\
aditivo e multiplicativo das igualdades por meio de ciclos \\
de rotação; \\
3. O professor deverá estipular um tempo para que cada grupo \\
comece a solucionar as equações de acordo com as atribuições \\
dadas inicialmente a cada participante; Em determinados \\
momentos curtos de tempo o professor sinalizará para que os \\
grupos troquem de equação em um sentido horário ou anti- \\
horário; A medida que o grupo muda de equação as funções \\
iniciais estipuladas para cada participante se invertem, ou \\
seja, os que estavam responsáveis pela parte algébrica assim \\
que mudarem de equação ficarão responsáveis pela parte \\
numérica; bem como os que estavam responsáveis pela parte \\
numérica, ficarão responsáveis pela parte algébrica; E assim \\
será feitos ciclos até que as equações sejam resolvidas; \\
4. Com o objetivo de evitar que os alunos tentem trapacear \\
de alguma forma, previamente para cada grupo serão pré- \\
escolhidos pelo professor um(a) aluno(a) para atuarem como \\
fiscais de cada equação, para que possam auxiliar o professor \\
na fiscalização das funções de cada participante dos grupos; \\
5. Todos vencem caso consigam resolver todas as equações de \\
forma conjunta corretamente ao final dos ciclos de rotação. \\
\hline
\end{tabular}

Fonte: Dados da pesquisa.

Na regra 03 do jogo criado em sua versão competitiva, os licenciandos frisam que quem conseguir resolver primeiro a equação vence, denotando neste sentido uma situação de competição entre os participantes. Ao analisarmos as regras desse mesmo jogo em sua versão cooperativa, percebemos que a ideia de adversários não aparece e com isso demonstra a ausência da necessidade de competição.

$\mathrm{Na}$ regra 04 de sua versão cooperativa, podemos notar que os licenciandos, ao adotarem a rotação dos estudantes em ciclos para resolverem as equações e mudarem suas funções à medida que rotacionam, contribuem para a interdependência desses jogadores, uma vez que suas funções não são fixas e muito menos as equações que os mesmos são responsáveis. Percebemos assim que a tática utilizada contribui para que os mesmos não fixem seus esforços em apenas uma equação, tentando terminar antes que os demais, neutralizando a ocorrência de uma prática competitiva. Também não podemos deixar de destacar a regra número 06 , que contribui para que os jogadores tenham a consciência de que precisam se esforçar para um resultado coletivo, onde um depende do outro.

Mediante isto, e das análises realizadas acerca de outras adaptações de jogos feitos pelos licenciandos para versões cooperativas, temos indícios que os objetivos das atividades propostas foram alcançados. E podemos concluir que os participantes desenvolveram suas habilidades cooperativas.

No que se refere ao segundo objetivo específico, analisar aspectos da apropriação das potencialidades argumentativas dos licenciandos ao longo do curso de extensão, apresentamos um recorte das análises feitas com os dados dessa fase do curso.

$\mathrm{Na}$ continuação das atividades do curso, fizemos um debate sobre agrotóxicos. Dividimos os participantes em dois grupos: um responsável por defender o uso de agrotóxicos (Pégasus e Hydra) e o outro (Andrômeda, Áquila e Orion) pela arguição contrária à utilização. Inicialmente, entregamos aos grupos argumentos apontados por internautas do "Yahoo Respostas" quando questionados "Agrotóxicos, você é contra ou a favor?", com o objetivo de os auxiliarem na construção de seus argumentos.

O debate aconteceu antes de realizarmos uma explanação teórica acerca da argumentação. Esta atividade foi pensada com a finalidade de mostrar aos licenciandos um pouco mais a frente, em uma autoanálise feita por eles ao verem a videogravação desse momento, se os mesmos argumentaram e se utilizaram os elementos da argumentação, mesmo sem nunca terem estudado teoricamente sobre ela. $\mathrm{O}$ recorte analisado se refere justamente a um desses momentos de autoanálise, após a explicação sobre argumentação. No entanto, para ficar compreensível nossa análise, mostraremos inicialmente o trecho sobre o qual os alunos posteriormente se autoanalisaram:

(T16) Pégasus: Eu sou... a favor do uso $\left({ }^{1}\right)$ consciente $\left({ }^{2}\right)$ do uso consciente $\left(^{1}\right)$ não abusar demais $\left({ }^{2}\right)$ por que... se a gente for parar pra pensar e ver os produtos (inaudível) mercado ( $\left.{ }^{1}\right)$ podem causar doenças o que for ( $\left.{ }^{1}\right)$ Todo mundo aqui gosta de galeto né? $\left(^{2}\right)$ Galetozinho $\left({ }^{2}\right)$ assado na brasa

(T17) Andrômeda: Quem é que não gosta, né?

(T18) Pégasus: Né? (') Aquela partezinha pretinha (inaudível) carvão fica alí (') pronto a galera come que nem sente $\left({ }^{2}\right)$

(T19) Andrômeda: É uma delícia

(T20) Pégasus: É cancerígeno.

(T24) Pégasus: Então... é... se a gente for pra... parte do orgânico também né (') vamo comparar (') com a situação econômica atual $\left({ }^{2}\right)$ a batata e o tomate já tá caro $\left({ }^{1}\right)$ e tem gente que não vive sem... a salada né? (') Imagina um orgânico que dá mais trabalho pra você... manter e cultivar e sair produto de qualidade (') pra ofertar no mercado ( $\left.{ }^{1}\right)$ então o valor vai ser ainda maior do que $\left(^{2}\right)$ o tradicional que a gente conhece que já tá caro (1) Então ninguém vai tá disposto a pagar isso ${ }^{(1)}$ E ninguém tá disposto a plantar $\left(^{1}\right)$ É o problema maior $\left({ }^{2}\right)$ (T25) Andrômeda: (inaudível) plantar

(T26) Pégasus: É por isso que eu sou a favor do uso consciente $\left({ }^{2}\right)$

(T27) Andrômeda: Sou totalmente contra /

(T28) Pégasus: E aí?

(T29) Andrômeda: É pra plantar

(T30) Pesquisador: E aí ó /

(T31) Andrômeda: Era pra cada um ter sua própria hortinha em casa e plantar seus próprios alimentos

(T32) Pesquisador: Foi o que Andrômeda? Repita aí, por favor.

(T33) Andrômeda: É melhor cada um ter a sua própria horta em casa e plantar seus próprios alimentos

Agora segue a autoanálise do trecho acima produzida pelos graduandos:

(T101) Pesquisador: E aí? 
(T102) Andrômeda: Agora teve resposta (FALA RINDO TODOS RIEM)

(T103) Pesquisador: Isso foi o que minha gente?

(T104) Andrômeda: Uma resposta!

(T105) Pesquisador: Foi uma resposta?

(T106) Andrômeda: Foi!

(T107) Pesquisador: Por que foi resposta?

(T108) Andrômeda: Porque foi o questionamento dele depois do contra-argumento dele aí a gente deu a resposta. Não sei dizer o porquê, mas eu sei que é resposta (ELES RIEM)

(T109) Pesquisador: O pra ter resposta, ela precisa responder quem?

(T110) Andrômeda: Ao contra-argumento!

(T111) Pesquisador: Você respondeu ali?

(T112) Andrômeda: Respondi! Fechando! (ELES RIEM)

(T113) Pesquisador: Então houve resposta minha gente? Houve resposta?

(T114) Áquila: Houve! (PEGASUS CONFIRMA COM O ROSTO)

(T115) Pesquisador: Houve. Então o que é que vocês podem me dizer? É argumentação ou não alí? O que tá acontecendo (T116) Andrômeda: (inaudível) com certeza! (ÁQUILA CONFIRMA COM O ROSTO QUE SIM)

(T117) Pégasus: (inaudível)

(T118) Andrômeda: Argumentamos sem saber (ELES RIEM)

Antes do turno (T27), em análises de outros trechos, os licenciandos haviam identificado a presença de dois elementos da argumentação: A e CA e Andrômeda havia se referido a necessidade de posteriormente ter uma resposta (R). Nos turnos (T27), (T29), (T31) e (T33), Andrômeda se posiciona após Pégasus ter comentado no turno (T24) sobre a inviabilidade de consumir produtos orgânicos alegando um preço de comercialização que as pessoas não pagariam. Na autoanálise, Andrômeda afirma com convicção que houve resposta ao CA apontado por Pégasus, como podemos confirmar nos turnos (T102), (T104) e (T108). Andrômeda respondeu ao contra-argumento de Pégasus, uma vez que disse que a solução estaria na criação de hortas em casa, onde as pessoas podiam plantar seus próprios alimentos.

Pudemos notar, no conjunto das nossas análises exemplificadas a partir do recorte acima, que no momento da autoanálise, os licenciandos conseguiram identificar os elementos que constituem um ciclo argumentativo (Leitão, 2011). Assim, concluímos que o objetivo da atividade foi plenamente alcançado.

Posteriormente, desenvolvemos com os licenciandos uma atividade sobre o tema da "Legalização da maconha e marcha da maconha" e outra sobre "Reforma trabalhista". Ambas tinham como foco a identificação dos elementos que constituem os argumentos. As expressões analisadas pelos licenciandos nas duas atividades também foram retiradas de uma página da plataforma "Yahoo Respostas". Para justificar a escolha desses temas, atentamos ao fato de que, para esta etapa do curso em que estudávamos sobre argumentação, buscamos assuntos de natureza já controversa em si. Isto é, o intuito dessa atividade, neste momento, ainda não estava voltado a discussões de como construir controvérsias referentes à disciplina de Matemática. No que se refere ao primeiro tema, o mesmo girava em torno da pergunta: A favor ou contra a legalização da maconha? Por quê? Concorda com a proibição da marcha da maconha? Por quê? ${ }^{4}$.

Vejamos abaixo um recorte da primeira atividade que mostra a análise feita pelos licenciandos para uma das respostas $^{5}$ da página da plataforma "Yahoo Respostas":

(T82) Hydra: Ele fala muito da vida dele, mas tem uma parte que ele fala que... Assim "Sou a favor da legalização", então ele tem um ponto de vista.

(T83) Pesquisador: Hum.

(T84) Hydra: Aí diz assim "tendo em vista que o álcool é liberado. Nesses acidentes de trânsito, você nunca ouviu falar que o motorista atropelou alguém ou causou um acidente porque tava doidão de maconha, mas sim porque estava embriagado, cheio de álcool na ideia. Então, é uma das circunstancias em que se prova que o álcool faz muito mais estrago na vida" das pessoas, então ele traz isso como uma justificativa pra dizer que o álcool é bem mais perigoso quando as pessoas consomem do que a maconha, por que ele pode causar acidentes, tirar vidas, deixar pessoas... é... em coma ou... Destruir famílias e mesmo assim o álcool tá liberado tranquilamente, você vai na esquina, pode comprar um... Uma bebida alcoólica em qualquer lugar você pode comprar. E é... Quando tem esses negócios desses acidentes só faz tocar na tecla que tava alcoolizado, mas aí não tem essa questão da proibição de... de.../.

(T85) Andrômeda: Com o álcool.

(T86) Hydra: (Continuando sua fala anterior) de consumir o álcool, tem a proibição sim de consumir e você ir dirigir não é? Que no caso é a lei seca, mas aí nem todos, vai da consciência de cada um também.

No recorte acima podemos perceber que Hydra aponta perfeitamente a presença do ponto de vista no turno (T82) e nos turnos (T84) e (T86), descreve a justificativa também identificada por ela na resposta analisada. Como vimos como exemplo no recorte anterior, os licenciandos conseguiram identificar os elementos de um argumento, muito embora algumas vezes tenham demorado um pouco para fazer essa identificação, bem como também tiveram dificuldades inicialmente de se utilizarem dos termos adequados para se referirem aos pontos de vista e justificativas. Mediante o exposto, podemos concluir que o objetivo esperado para esta

4 Todas as perguntas e respostas utilizadas que foram retiradas do site "Yahoo Respostas" foram mantidas literalmente de acordo com as escritas de seus autores. O mesmo acontece com as transcrições dos debates na sala de aula trazidos nos recortes aqui analisados. Nelas, a transcrição é feita literal, preservando a forma como os estudantes falam. Por esse motivo percebemos tanto abreviações quanto alguns erros ortográficos.

5 Resposta analisada: "Olha, moro numa casa com outras pessoas que passam o dia inteiro fumando maconha. EU não suporto aquele fedor, mas preciso morar lá. E nisso, vejo que não atrapalha em nada a vida deles. Não suporto maconha, não quero pra mim, mas acho que se os outros querem, o problema é deles. Sou a favor da legalização, tendo em vista que o álcool é liberado. Nesses acidentes de trânsito, você nunca ouviu falar que o motorista atropelou alguém ou causou um acidente porque tava doidão de maconha, mas sim porque estava embriagado, cheio de álcool na ideia. Então, é uma das circunstancias em que se prova que o álcool faz muito mais estrago na vida da pessoa. Quanto à proibição da marcha, aquilo foi um absurdo. Parece que ainda estamos numa ditadura. cadê a liberdade de expressão? Direitos iguais pra todos. Se tem a Parada Gay, que é uma marcha contra a homofobia, os pró-maconha tem que ter a sua marcha também. Beijinhos" (ACERVO DA PESQUISA, 2018). 
atividade também foi alcançado.

No decorrer de outra atividade do curso de extensão, os estudantes tinham como objetivo identificar ações discursivas da professora em recortes que continham turnos de fala de uma turma de sexto ano em uma aula de História, discutindo sobre o tema Escravidão (De Chiaro \& Leitão, 2005). Relembramos que as ações que criam condições pragmáticas para a emergência da argumentação, por isso chamadas ações pragmáticas, são as que dão margem para o surgimento de perspectivas alternativas sobre determinados temas, possibilitando a efetivação do debate argumentativo na sala de aula. As que sustentam a argumentação, a partir da participação do professor no debate, são as ações argumentativas. E as que trazem conteúdos e formas de raciocínio próprios de um dado campo de conhecimento e legitimam o conhecimento construído são as ações epistêmicas.

Um dos trechos dessa aula de História analisados pelos estudantes se referiu a um momento de debate entre dois alunos, José e Luís, em que José questionava a compreensão de Luís sobre o tema da superioridade entre brancos e negros. Segue um pequeno recorte que servirá para entendermos a análise dos estudantes sobre a fala da professora nesse caso:

(T375) Luís: Não eu não achei que o negro era superior ao branco não.

(T376) José: (continuando um raciocínio iniciado antes sobre uma fala de Luís) como se o negro estivesse acostumado a ser escravo.

(T377) Professora: Submisso, não é superior.

Vejamos as afirmativas dos graduandos no que se refere a classificação do tipo de ação discursiva da professora:

(T43) Andrômeda: Eu botei epistêmico

(T44) Áquila: Epistêmica!

(T45) Andrômeda: Epistêmica eu coloquei!

(T46) Pesquisador: Elas colocaram epistêmica Orion, e você?

(T47) Orion: Eu botei argumentativa! (ELE RI) Eu lendo agora eu vi que é epistêmica, que ela traz aí uma... Ela traz aí uma ideia aí, ela diz "Submisso, não é superior.", ela traz, ela já traz um... algo.../

(T48) Andrômeda: Um conhecimento!

(T49) Áquila: Conhecimento!

(T50) Orion: É um tipo de conhecimento (...)

(T57) Pesquisador: Sim, mas se você colocou argumentativa foi por algum motivo. Quando ela diz "Submisso, não é superior".

(T58) Orion: Por que (inaudível) ela estava no meio da conversa né? Aí eu achei que... por ela estar no meio da conversa ela traz aí pra... aumentar mais o debate né?

(T59) Pesquisador: Ela se posiciona aí nesse caso? Sim ou não?

(T60) Andrômeda: Então é argumentativa também!
Pelo o que podemos ver nos turnos (T43) e (T44), Hydra e Áquila conseguem identificar o tipo de ação discursiva da professora no recorte analisado. Elas definem esta ação de forma correta, uma vez que a professora no turno (T377) se utiliza de conceitos de um determinado campo de conhecimento, o que configura uma ação epistêmica. Orion no turno (T47), embora no início não tenha identificado esta ação, reconhece que suas colegas estão corretas. Contudo, quando questionado sobre o porquê de ter pensado na ação argumentativa, explica que fez essa colocação uma vez que a professora também estava se posicionando no debate, o que de fato está acontecendo, pois, ao trazer esse conteúdo, ela o faz marcando a sua posição sobre o conceito de superioridade que vinha sendo discutido. Andrômeda, no turno (T60), concorda com a explicação feita por Orion no turno (T58). Nesse sentido, os licenciandos conseguem identificar corretamente duas ações em uma mesma fala analisada da professora. Em outros momentos desta atividade, os mesmos também conseguem identificar a ação discursiva pragmática. Portanto, percebemos que os licenciandos conseguiram identificar corretamente as ações discursivas por meio da análise dos turnos que versavam sobre a fala da professora. O objetivo dessa atividade foi totalmente cumprido e atingido pelos licenciandos.

Na próxima parte analítica, buscamos alcançar resultados e respostas para o terceiro objetivo específico da pesquisa, o de analisar elementos relacionados a apropriação das potencialidades cooperativas e argumentativas pelos licenciandos na elaboração dos critérios necessários para a construção de um jogo cooperativo argumentativo. Propusemos como atividade que os licenciandos explicassem os critérios elaborados por eles acerca do que achavam necessário para a criação de um jogo cooperativo argumentativo. Comparamos os critérios por nós elaborados com os dos licenciandos de forma a analisarmos até que ponto esses critérios convergiram.

Trazemos aqui recortes de nossas análises no que se refere a alguns dos critérios criados pelos licenciandos ${ }^{6}$, estabelecendo relações que julgamos existir entre esses e nossos critérios ${ }^{7}$. Nosso primeiro critério foi contemplado nos critérios 01 e 02 dos licenciandos, em ambos eles apontam para uma prática cooperativa e para a busca por uma solução colaborativa no objetivo do jogo. Andrômeda diz: "Vencem só se cooperarem. Tem que ficar bem claro isso, que tipo se eles não cooperar entre si não vai ter ganhador, vai ter tudo perdedor" (Dados do acervo da pesquisa, 2018).

6 Critérios dos Licenciandos: 1. Todos vencem (se, e somente se, todos cooperarem); 2. Cooperar para atingir o objetivo do jogo; 3 . Presença de uma controvérsia; 4. Todos têm que argumentar, analisar os argumentos (deles mesmos e dos outros); 5 . Entrar em consenso para atingir o objetivo do jogo; 6. Todos vencem se cooperarem e argumentarem para se atingir o objetivo do jogo.

7 Critérios para jogos cooperativos argumentativos construídos pelos pesquisadores mediante estudos de Orlick (1978) e Leitão (2011): Regras que apontem; 01. Que o caminho para o alcance do objetivo do jogo está na interdependência dos participantes demandando atitudes cooperativas; 02 . Que o alcance do objetivo do jogo deve estar relacionado à resolução de uma controvérsia; 03. Que a atitude cooperativa na resolução da controvérsia envolve necessariamente a abertura para o diálogo entre os participantes; 04. Que a abertura ao diálogo entre os participantes está vinculada ao debate de diferentes perspectivas em um discurso argumentativo; 05. Que o debate de diferentes perspectivas envolve a reflexão das suas próprias posições à luz das posições do outro; com vias a uma solução colaborativa. 
Ao explicar o primeiro critério, ela enfatiza a sua importância. O que é bastante pertinente, pois, segundo Orlick (1978), para que um jogo seja cooperativo devemos levar em consideração que deve existir uma interdependência entre os jogadores. Enfatizar que esse critério precisa estar contemplado nas regras do jogo significa que quem joga deverá ter ciência de que todos dependem uns dos outros para ganhar e, caso não haja cooperação, abre-se a possibilidade de competição, o que acarreta a perda do jogo.

O nosso segundo e terceiro critérios também são contemplados em um dos critérios criados pelos licenciandos, de forma mais específica, no critério de número 03. O recorte abaixo nos ajuda a compreender como se pauta essa contemplação. Assim lemos:

(T49) Andrômeda: Então a gente deveria trazer explícito tipo, é... ao se deparar com uma controvérsia eles deveriam entender que eles não podem ser adversários nesse sentido quando encontrar a controvérsia, embora eles tenham opiniões diferentes eles vão ter que argumentar entre si para encontrar qual o melhor caminho para seguirem e não entrar em conflito né? Mais ou menos isso. Como a gente bota?

(T50) Orion: É... bota assim: Que a controvérsia não pode ser motivo. A controvérsia não pode ser motivo para que eles acreditem é... que eles tenham o outro como adversário (T51) Pesquisador: Por que isso é importante?

(T52) Orion: Por que nós tamos num jogo cooperativo né? Se eles confundirem essa parte de controvérsia, ela pode levar um caminho meio que competitivo. Mas, mas aí como a regra do jogo já vai tá bem claro, acho que eles vão fugir muito disso. Porque eles vão divergir, em alguns momentos eles vão divergir entre si, mas essas divergências não é no sentido de... é... por exemplo, de um se sair melhor do que o outro, mas sim de aprenderem e... buscar /

(T53) Áquila: O melhor caminho, a melhor forma de vencer aquilo para atingir o objetivo do jogo principalmente. (Dados do acervo da pesquisa, 2018).

Embora o critério 03 criado pelos licenciandos apenas faça menção a presença de uma controvérsia, chamamos a atenção para como estes discutem sobre o papel da controvérsia dentro de um jogo cooperativo argumentativo. Andrômeda no turno (T49) é bem categórica ao explanar que ao se depararem com a controvérsia os jogadores precisam ter ciência de que a busca pela solução dessa controvérsia, feita por meio de um diálogo, deve se dar por intermédio da cooperação e não como uma forma de embate, de forma competitiva, como podemos constatar na fala de Orion nos turnos (T50) e (T51). Isso se alinha ao que propomos em nosso critério de número 03. Ainda sobre a controvérsia, Áquila, no turno (T53), complementa a fala de Orion no turno (T52) dizendo que os jogadores deverão decidir qual o melhor caminho a seguir para atingir o objetivo do jogo, ou seja, que a resolução da controvérsia decidida pelos jogadores lhes encaminhará para atingir o objetivo do jogo, caso que apontamos em nosso critério 02.

Percebemos que todos os critérios elencados pelos licenciandos de alguma forma estão inseridos nos critérios por nós propostos. Concluímos que os licenciandos se apropriaram das potencialidades cooperativas e argumentativas uma vez que conseguiram construir critérios que propuseram a união dessas duas estratégias.

No que tange ao quarto objetivo específico da pesquisa, analisar a potencialidade cooperativa e argumentativa do jogo elaborado pelos licenciandos, analisamos os passos que os graduandos seguiram na criação do jogo e averiguamos se as potencialidades cooperativas e argumentativas foram construídas e materializadas neste jogo depois de todas atividades do curso de extensão. O jogo criado, nomeado pelos licenciandos de "Corrida das funções" para alunos do $9^{\circ}$ ano do ensino fundamental.

Os licenciandos definiram as seguintes regras para o jogo "Corrida das funções": 1) Os participantes devem "entrar" no carro e se posicionar no início. Uma coisa muito importante acontece antes de iniciar o jogo: os participantes que estiverem dentro do carro recebem uma quantia para todos equivalente a $\mathrm{R} \$ 10,00 ; 2$ ) Vocês terão que jogar o dado (Dado com seis faces: Três delas com o número 01 e as outras três com o número 02 ) e o número que sair será o número de casas que deverão percorrer; 3) Cada casa tem uma cor, essa cor significa um nível diferente para cada pergunta sobre função que será feita aos participantes; 4) Para isso, existem três caixas coloridas: amarela, verde e vermelha; o nível de dificuldade das questões está diretamente ligadas às cores (amarela: fácil, verde: médio e vermelho: difícil); 5) Além das cores, vocês podem chegar a alguns imprevistos, como ter que parar para abastecer o carro, parar no lava jato ou na oficina. Se isso acontecer, você precisará usar o dinheiro que tem para custear ou optar por responder a algumas perguntinhas, se acertar, conseguirá usufruir do serviço sem pagar nada; 6) A cada acerto vocês ganham $R \$ 5,00$. Se por acaso vocês errarem, podem optar por responder outra questão e caso a acertem podem permanecer na casa, mas isso lhes custará $\mathrm{R} \$ 5,00$. Caso não respondam a questão, vocês devem voltar uma casa; 7) É necessário jogar com duas ou mais pessoas; 8) Os participantes terão que fazer todas as atividades em conjunto; 9) Durante as questões/problemas os participantes terão que dialogar entre si para encontrar a melhor resposta; 10) Em hipótese alguma um participante pode responder sozinho; 11) É necessário que todos deem suas opiniões sobre

8 Introdução feita pelos Licenciandos sobre o Jogo: Vocês estão prestes a participar de uma corrida das funções, mas afinal, o que é isso? Nós já estudamos um pouco sobre funções e precisamos colocar em prática o que aprendemos! Existe aqui um caminho a ser percorrido. Vocês devem se posicionar na direção de início e jogar o dado; o número que aparecer corresponderá ao número de casas que vocês vão percorrer. Entretanto, em cada lugar que seu carro estacionar, vocês encontrarão um problema para resolver. Além desses problemas, alguns eventos extras podem ocorrer no caminho, como: precisar ir à oficina, abastecer o carro ou ir ao lava jato. Se isso acontecer, espero que vocês estejam preparados financeiramente para pagar, caso escolham a opção de utilizar o serviço disponível; ou podem responder o desafio e permanecer na casa caso o acertem. 
o problema, debatam entre si e cheguem a um consenso; 12) Isso significa que eles terão que jogar juntos para que todos consigam vencer; e 13) Se essas regras forem descumpridas, automaticamente perderão o jogo.

Analisamos as potencialidades desse jogo de acordo com os critérios que elaboramos. Para tentar identificar o cumprimento dos critérios, nos utilizamos dos descritores ${ }^{9}$ criados por nós a partir desses critérios. Fizemos uma análise nos utilizando das regras pensadas para o presente jogo, bem como das questões elaboradas pelos licenciandos que também compõem o mesmo. Vejamos um recorte dessa análise:

Quadro 7 - Jogo criado pelos licenciandos (Relações: Critério Descritor - Regras)

\begin{tabular}{|l|l|}
\hline \multicolumn{1}{|c|}{ Critério e Descritor (D) } & \multicolumn{1}{|c|}{ Regras } \\
\hline & $\begin{array}{l}\text { 9) Durante as questões/ } \\
\text { problemas os participantes } \\
\text { terão que dialogar entre si para } \\
\text { encontrar a melhor resposta. }\end{array}$ \\
$\begin{array}{l}\text { Critério: Deixe claro que } \\
\text { o caminho para o alcance } \\
\text { do objetivo do jogo está na } \\
\text { cooperação; Interdependência hipótese alguma um } \\
\text { participante pode responder } \\
\text { sozinho. }\end{array}$ \\
$\begin{array}{l}\text { 12) Isso significa que eles } \\
\text { cooperativa qua que jogar juntos para } \\
\text { jogadores; não deixe margem } \\
\text { para atitudes competitivas. }\end{array}$ & $\begin{array}{l}\text { que todos consigam vencer. } \\
\text { forem Se essas regras } \\
\text { automaticamente perderão o } \\
\text { jogo. }\end{array}$ \\
\hline
\end{tabular}

Fonte: Dados da pesquisa.

A interdependência cooperativa, segundo Orlick (1978), está relacionada à compatibilidade de metas, ou seja, quando a meta a ser alcançada por um jogador é comum a todos os outros jogadores. Em poucas palavras, em um jogo cooperativo esta inter-relação deve ser muito evidente, pois, ou todos ganham ou todos perdem, perspectiva que podemos identificar na regra de número 13 do jogo criado.

Ao analisarmos as regras do jogo criado pelos licenciandos, podemos notar que quatro delas denotam a interdependência entre os jogadores: uma é a 13, já mencionada. $\mathrm{Na} 9$, notamos essa interdependência quando a mesma aponta que os jogadores devem "dialogar entre si", buscando eliminar a ideia de resolver os problemas de forma individual, enfatizada na regra $10 . \mathrm{Na} 12$, enfatiza-se que para que se vença o jogo os participantes deverão jogar juntos ou, o perderão. Concomitantemente, ao darem ênfase a essa interdependência, também identificamos a tentativa de não dar margem para atitudes competitivas, uma vez que não fazem menção, em nenhum momento, a "adversários", pelo contrário, enfatiza-se sempre a necessidade de agir dentro do jogo de forma conjunta. Logo, podemos concluir que o jogo atende ao primeiro critério.

Como as controvérsias estão inseridas dentro do jogo em forma de problemas, trazemos um exemplo de como os licenciandos pensaram sobre elas fazendo uma análise de um dos problemas ${ }^{10}$. Notamos que os licenciandos conseguiram prever uma excelente controvérsia. Ao se depararem com esse problema, alguns dos jogadores poderiam alegar que a locadora "B" seria mais vantajosa na medida em que cobrava um valor fixo mais barato. Todavia, isso não é verdade, pois, a "A" oferece um valor bem menor por $\mathrm{Km}$ excedido. Se fizerem as contas, concluirão que a empresa escolhida de forma a economizar seria a "A". Essa concepção equivocada comumente poderia se apresentar na resolução desse problema e entrar em confronto com o posicionamento correto de quem atentou para o valor cobrado por $\mathrm{Km}$ rodado. Consequentemente, como as regras do jogo exigem um consenso, haveria a necessidade de convencimento entre ambas as partes que discordassem, acarretando a argumentação. Nesse sentido, os licenciandos conseguiram prever e colocar dentro de um jogo a possibilidade dessa controvérsia.

Mediante nossas análises, concluímos que o jogo construído pelos licenciandos atendeu aos critérios por nós elaborados e que podemos considerá-lo potencialmente cooperativo argumentativo, uma vez que suas regras denotam a iminência da cooperação e da utilização da argumentação durante a dinâmica do mesmo. Salientamos que compreendemos a necessidade de uma revisão no jogo para que fique mais compreensível por meio das regras e, para que possamos comprovar se o mesmo proporciona a cooperação e a argumentação de forma conjunta, devemos aplicá-lo futuramente. Por fim, ainda assim, destacamos que o objetivo da atividade foi alcançado pelos licenciandos.

\section{Considerações Finais}

Com base nos apontamentos dos resultados podemos constatar os impactos do curso de extensão na formação destes licenciandos. Em linhas gerais, os graduandos tiveram a oportunidade de conhecer uma modalidade de jogo que até então não conheciam, permitindo que os mesmos expandissem suas visões acerca das estratégias que possam vir a serem utilizadas em sala de aula. Conheceram um tipo de discurso capaz de promover o pensamento crítico e reflexivo, o da argumentação, e de como podem implementá-la usando ações específicas para potencializar o trabalho na sala de aula.

Os participantes construíram também reflexões acerca da

\footnotetext{
9 Descritores: D1. Não deixe margem para atitudes competitivas: Interdependência cooperativa entre os jogadores; D2. Presença de uma controvérsia ou possível controvérsia de acordo com o tema/conteúdo a ser trabalhado no jogo; D3. Dependência de articulação para alcançar-se o objetivo do jogo, caso não haja não há solução isolada para a controvérsia; D4. Presença de regras que deixem claro que esse tipo de diálogo tem que acontecer; D5. Solução/Alcance do objetivo do jogo através de um consenso de forma cooperativa; controvérsias iniciais se convergem em consenso final.

10 Problema: A locadora de carros "A" cobra pelo aluguel de carros um valor fixo de R\$70,00 para até $100 \mathrm{Km}$ rodados e R\$ 0,45 por cada Km ultrapassado. A locadora "B" cobra o valor fixo de $\mathrm{R} \$ 60,00$ para até $100 \mathrm{Km}$ rodados e $\mathrm{R} \$ 0,70$ por cada Km ultrapassado. Qual das empresas deve ser escolhida por um cliente que pretende rodar $150 \mathrm{Km}$ ? (Dados do acervo da pesquisa, 2018).
} 
possível interligação entre a cooperação e a argumentação. Isto exigiu deles um grande esforço de reflexão sobre como podem construir intervenções que tratem sobre estas modalidades não só de forma separada, mas de forma conjunta, como foi o jogo construído ao final do curso de extensão. Em linhas mais específicas, os impactos deste curso permeiam discussões mais estreitas, tais como a utilização de uma modalidade de jogo (o cooperativo) que não é comentada e nem explorada no curso de graduação destes licenciandos. Julgamos que isto é algo que deveria ser discutido, pois, é uma modalidade tão essencial quanto às de jogos na modalidade competitiva. Outro impacto se refere à reflexão de como as aulas da disciplina de Matemática podem ser trabalhadas com o intuito de promover um diálogo capaz de fomentar o pensamento crítico dos estudantes por intermédio da argumentação.

Os licenciandos durante o curso de extensão, de forma mais específica a partir do segundo momento, tiveram contato com atividades práticas sobre argumentação e refletiram sobre como utilizar esta argumentação em sala de aula, assim como utilizá-la em um jogo "cooperativo argumentativo". Isso nos permite dimensionar o quanto a presente experiência dos licenciandos nestas atividades propiciou aos mesmos uma formação sobre como se utilizar da argumentação em um contexto cooperativo. Com base nisto, concluímos que o objetivo do estudo foi alcançado. A pesquisa nos permitiu ampliar nossas visões acerca dessas duas estratégias e identificar novos caminhos a serem trilhados no sentido de expandir nossas compreensões sobre o tema, como por exemplo, o conceito de controvérsia no ensino da Matemática. Vimos ainda a necessidade de aplicarmos o jogo criado pelos licenciados, de forma a testar na prática suas potencialidades cooperativas e argumentativas.

Entendemos por fim que a contribuição central de nossa pesquisa está em refletirmos sobre uma proposta pedagógica que une duas estratégias que juntas assumem um importante papel na formação de indivíduos cooperativos, críticos e reflexivos.

\section{Referências}

Brotto, F. O. (2013). Jogos cooperativos: o jogo e o esporte como um exercício de convivência. (4a ed.) São Paulo: Palas Athena.

De Chiaro, S., Leitão, S. (2005). O papel do professor na construção discursiva da Argumentação em Sala de Aula. Psicologia, Reflexão e Crítica, 18, 3, 350-357.
De Chiaro, S., Aquino, K. (2017). Argumentação na sala de aula e seu potencial metacognitivo como caminho para um enfoque CTS no ensino de química: uma proposta analítica. Educação e Pesquisa, 43, 411-426.

Grando, R. C.(1995). Ojogo [e] suas possibilidades metodológicas no processo ensino-aprendizagem da matemática. Campinas: Universidade Estadual de Campinas.

Huizinga, J. (2000). Homo Ludens. São Paulo: Perspectiva.

Itacarambi, R. R. (2013). Jogo como recurso pedagógico para trabalhar matemática na escola básica: ensino fundamental. São Paulo: Editora Livraria da Física.

Kishimoto, T. M. (1994). O jogo e a Educação Infantil. São Paulo: Pioneira.

Leitão, S. (1999). Contribuições dos estudos contemporâneos da argumentação à uma análise psicológica de processos de construção de conhecimento em sala de aula. Arquivos Brasileiros de Psicologia, 1, 91-109.

Leitão, S. (2007) Processos de construção do conhecimento: a argumentação em foco. Pro-Posições, 18, 75-92.

Leitão, S. (2011). O lugar da argumentação na construção do conhecimento em sala de aula. In S. Leitão \& M. C. Damianovic. Argumentação na escola: o conhecimento em construção pp. 13-46. Campinas: Pontes Editores.

Leitão, S. (2013). Uma perspectiva de análise do papel da argumentação em ambientes de ensino-aprendizagem. In K. Moutinho, P. Villhachan-Lyra, \& A. Santa-Clara. Novas tendências em psicologia do desenvolvimento: teoria, pesquisa e intervenção, pp. 1-17. Recife: UFPE.

Leitão, S., De Chiaro, S., Cano, M. (2016). El debate crítico. Un recurso de construcción del conocimiento en el aula. Textos de Didactica de la Lengua y de la Literatura, 73, 26-33.

Lopes, C. A. S., Rodrigues, K. C., Rodrigues, S. R. C. (2020). Jogos cooperativos e argumentação: potencialidades para a promoção do pensamento crítico e reflexivo no ensino de matemática. REnCiMa, 11, 3, 244-263. https://doi. org/10.26843/rencima

Mattos, R. A. L. (2009) Jogo e Matemática: Uma relação possível. Salvador: R. A. L.

Orlick, T. (1978) Vencendo a competição. São Paulo: Círculo do livro.

Pimentel, A. (2008). A ludicidade na educação infantil: uma abordagem histórico-cultural. Psicologia da Educação, 26, 109-133.

Vygotsky, L. S. (1993). Pensamento e Linguagem. São Paulo: Martins Fontes.

Vygotsky, L. S. (2010). A formação Social da Mente. São Paulo: Martins Fontes. 